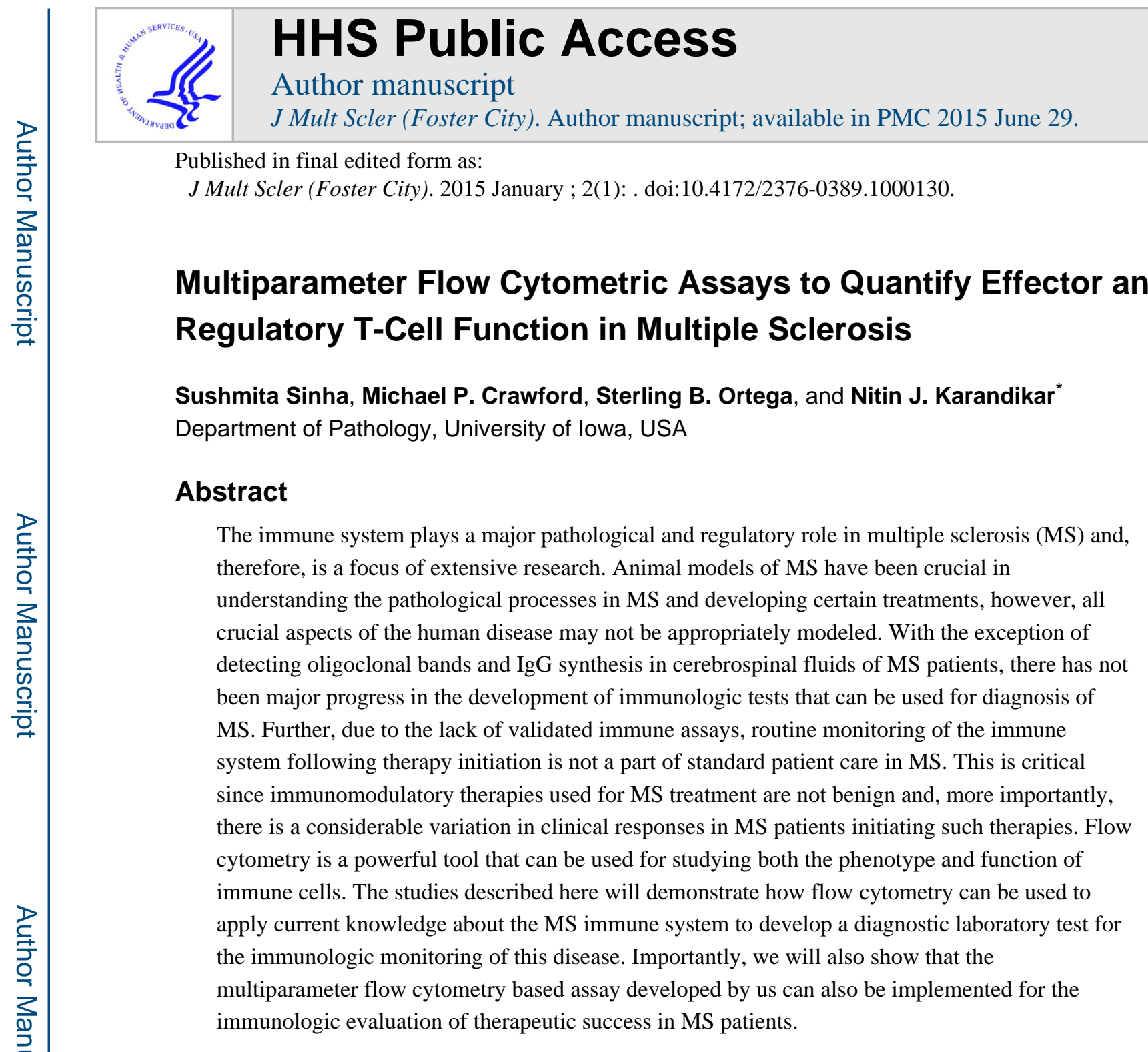

Keywords

Multiple sclerosis; Flow cytometry; T-cell responses; Therapy monitoring

\title{
Introduction
}

The precise etiology of multiple sclerosis (MS) is not clearly understood. Epidemiological studies suggest that both genetics and environment, particularly inciting viral infections, may play a role in the pathogenesis of MS [1-3]. The vast majority of MS patients are diagnosed during their third or fourth decade of life, resulting in long term morbidity. The histology of the lesions in MS is characterized by perivascular, mononuclear infiltrates and demyelination in the central nervous system (CNS), features suggestive of immunemediated destruction $[1,4]$. In addition, $\mathrm{T}$ cell responses to various CNS antigens have been

This is an open-access article distributed under the terms of the Creative Commons Attribution License, which permits unrestricted use, distribution, and reproduction in any medium, provided the original author and source are credited.

*Corresponding author: Nitin J. Karandikar, MD, PhD, Department of Pathology, University of Iowa, 200 Hawkins Dr. Iowa City, IA 52242, Tel: 319-384-9609; nitin-karandikar@uiowa.edu. 
demonstrated in MS patients. These putative MS target antigens include myelin basic protein (MBP), proteolipid protein (PLP), myelin-associated glycoprotein (MAG), and myelin oligodendrocyte glycoprotein (MOG), among several others. Interestingly, responses to some of these myelin antigens have also been demonstrated in healthy individuals and may be qualitatively different from those in MS patients [5-10].

A significant amount of research has been conducted into the immune processes that characterize MS, resulting in an improved understanding of the immune status of these patients. Flow cytometry has been extensively used by MS researchers worldwide to gain insights into the immune system of MS patients. The technology has been successfully used to identify key immunological pathways that are defective in MS patients and might predispose them to the disease. However, as yet there is no immunologic test available for the diagnosis of MS, with the exception of CSF evaluation for oligoclonal bands and local IgG synthesis, which is neither a sensitive nor a specific test. It is possible that only certain subsets of MS patients have a dysfunction in the immune system and are appropriate targets for the immune-based therapies and, therefore, development of an assay to evaluate $\mathrm{T}$ cell function will be an important step toward resolving this issue. The availability of such an assay would also enable immune monitoring of patients placed on therapies and may provide insight into the commonly observed idiosyncratic therapeutic responses. In this review we will summarize our novel flow cytometry based approaches to characterize the autoreactive responses and their functional status in relapsing remitting MS (RRMS) patients.

\section{Diagnosis of MS}

The diagnosis of MS is made by a combination of clinical parameters (medical history, clinical exam) and ancillary testing parameters (such as MRI, CSF oligoclonal banding/Ig synthesis, measurement of evoked potentials, optical coherence tomography, among others). Importantly, there is no "MS-specific" diagnostic test. Thus, several criteria have been proposed to aid the diagnosis and monitoring of this disorder, which may potentially be a conglomeration of several distinct processes or diseases. The general diagnosis of MS today is based on finding evidence for two or more white matter lesions on at least two occasions, as proposed since 1965, and later expanded in 1983 and 2001 [11,12]. This was followed by a more recent modification of the McDonald Criteria that would lead to a more rapid diagnosis of MS [13]. Over the years, certain findings on MRI examination have allowed the diagnosis of "definite MS" even during the first clinical episode, thereby promoting the early treatment of patients. Although a controversial issue, it has also been observed that early treatment of this disease provides most effective limitation of progressing disability.

Our understanding about the T cell-mediated immune processes that underlie MS pathogenesis and regulation has improved considerably over the past several years [14-17] However; the laboratory tests available for MS do not utilize this advanced level of knowledge. Diagnosis of MS still depends on a combination of radiographic, clinical and laboratory criteria. The only immunologic tests used for the diagnosis of MS are detection of oligoclonal bands and immunoglobulin synthesis testing in cerebrospinal fluid (CSF).

However, these tests do not take into consideration the clinical heterogeneity associated with 
MS patients. This picture is further complicated by the fact that there is a considerable variation in the clinical responses following immunomodulatory therapies in MS patients. Moreover, routine monitoring of the immune system following therapy initiation is not a part of standard patient care. This is partly due to the lack of robust, reproducible and clinically relevant assays that can be used to track the changes in the immune system overtime in MS patients on immunomodulatory therapies. Development of a simple and sensitive immune assay that can be used by several labs for early diagnosis and therapy management in MS patients would make a major impact on MS patient care. The prominent requirement of such an assay would be its ability to differentiate MS patients from patients with other neurologic disease and healthy subjects. While the generation of such a test has been technologically difficult, we have developed a flow cytometric based proliferation assay that allows for the detection, quantification and phenotyping of CNS-reactive T cell responses following a relatively short-term in vitro culture [16,18-21]. From several reports by others and us, we know the following:

1. MS patients harbor $\mathrm{CD} 4+$ and $\mathrm{CD} 8+\mathrm{T}$ cell responses targeted to CNS autoantigens.

2. Healthy subjects also harbor such responses. Moreover, the magnitude of these responses appears to be similar between MS patients and healthy subjects.

3. However, in contrast to the similar magnitudes, CNS-specific T cell responses from MS patients are functionally distinct from those in healthy subjects, in that they show evidence of in vivo exposure to the antigens. Thus, CNS-targeted T cells from MS patients are less dependent on CD28-mediated costimulation [5], are more differentiated toward effector status [16], have greater numbers of HPRT mutations [22] and thus, exhibit a memory/effector phenotype.

4. Furthermore, these $\mathrm{T}$ cell responses can be preferentially stimulated by the use of low doses of CNS antigens and the addition of IL-7 to the cultures [23,24].

The current knowledge can be exploited by a flow cytometry based assay system to develop and validate an assay system for the immunologic monitoring of MS.

\section{Flow cytometry based detection, enumeration and cytokine profiles of T-cell responses}

Flow cytometry is a sensitive and reliable technology to accurately delineate, characterize and quantify antigen-specific $\mathrm{T}$ cell responses. The ability to quantify antigen-specific $\mathrm{T}$ cells was recently revolutionized by tetramer technology $[25,26]$. While this assay has greatly enhanced the ability to accurately quantify a $\mathrm{T}$ cell response, it is limited by the requirement for a known target peptide-MHC complex. As is obvious in a complex human disease such as MS, this would not be a feasible approach since a comprehensive panel of target epitopes, in diverse MHC settings, remains elusive. In fact, even in bettercharacterized disease settings such as viral infections, it is not possible to precisely predict the predominant responsive epitopes [27]. The problem of epitope spreading during the autoimmune disease course further compounds this issue. A very promising approach to measure and characterize $\mathrm{T}$ cell responses utilizes the intrinsic ability of $\mathrm{T}$ cells to make cytokines in response to antigenic challenge [28-33]. Hence, bulk cells can be challenged with a multitude of antigens and their cytokine response characterized and quantified, 
without the prior knowledge of MHC restriction or peptide antigenic epitopes. The added advantage of such cytokine assays is the measurement of a relevant $\mathrm{T}$ cell effector function and non-dependence on simple proliferation as a read out. Many studies in MS have shown correlation between disease progression and the production of "Th1-type" cytokines such as IFN- $\gamma$, IL-2, IL-12 and TNF-a [34]. Pro-inflammatory cytokines are thought to be crucial for the initiation and amplification of brain lesions and direct myelin damage in MS [35-37]. Regulatory "Th2-type" cytokines, such as IL-4, IL-5, and IL-10, may be responsible for downregulating pro-inflammatory processes [34]. There appears to be a continual balance between the pro-inflammatory and anti-inflammatory immune responses that are potentially amenable to therapeutic alteration $[38,39]$. One major methodology that has been utilized in MS to quantify myelin-specific cytokine responses is the ELISA-based ELISPOT assay [30,40-43]. Whereas ELISPOT assays provide excellent quantification of the cytokine response to a specific antigen at bulk population levels, they do not characterize the nature of the cell producing the cytokine. More recent studies, from other areas of immunology, have demonstrated great utility of a flow cytometry-based assay in characterizing and quantifying $\mathrm{T}$ cell function [31,44-46]. In these assays, retained intracellular cytokines are detected by staining with fluorochrome-tagged anti-cytokine antibodies. These cells can be precisely quantified by flow cytometers and, more importantly, accurately phenotyped by staining cell surface markers such as CD3, CD4 and CD8, for example. In addition, the reactive populations are amenable to flow-based cell sorting, enabling further molecular characterization of precisely defined antigen-specific cells.

Another approach in these situations has been the flow cytometric equivalent of the in vitro proliferation assay. The major advantage of this assay is the ability to phenotype the proliferating cells. This strategy detects antigen-induced cellular proliferation by utilizing a green fluorescent dye, 5 (and 6)-carboxyfluorescein diacetate succinimidyl ester (CFSE), and has been used previously in many systems to detect dividing cells [47-52]. The cells are first stained with CFSE and then subjected to different culture conditions. Dividing cells can then be detected by sequential halving of their fluorescence and, at the same time, phenotyped by staining for cell surface markers or intracellular cytokines. This also helps to amplify the cell numbers thereby facilitating the flow sorting of antigen-specific cells. Immunophenotypic characterization of autoreactive $\mathrm{T}$ cells in short-term in vitro cultures has been a technologic challenge due to their low precursor frequency and low avidity. We have recently developed and standardized the CFSE-based proliferation assay system to successfully study antigen-specific T cell responses in MS [18,19,53].

\section{Evaluation of CNS-reactive CD4+ and CD8+ T cell responses in MS patients by flow cytometry}

Our extensively published data demonstrates the usefulness of flow cytometric approaches to directly detect, quantify and phenotype antigen-specific $\mathrm{T}$ cells in human disease $[18,19,53]$. Using these approaches, we have performed a detailed evaluation of the CNStargeted reactivity in MS patients and demonstrated a high prevalence of CNS-specific autoreactive CD8+ T cell responses [18]. This was a novel observation since studies on neuroantigen specific $\mathrm{T}$ cell responses were restricted only to CD4+ T cells. Figure 1 shows results from a CFSE-based proliferation assay performed on PBMC from an untreated MS 
patient. After CFSE staining, cells were cultured in vitro in the presence of several CNS autoantigens (multiple pools of serial overlapping peptides representing 9 putative CNS target proteins). On day 7 of culture, cells were stained with antibodies against CD3, CD4 and CD8. Gated populations of CD4+/CD8- and CD8+/CD4- T cells are shown. The numbers represent the proportion of gated CD8+ T cells (green) or gated CD4+ T cells (red) that were in the proliferating fraction $(\mathrm{PF})$ on day 7. Akin to traditional proliferation assays, we utilize the proliferation fraction $(\mathrm{PF})$ values to calculate $\Delta$ Proliferating Fraction $(\Delta \mathrm{PF})$ by subtracting the background proliferation (no antigen) from antigen-induced proliferation. Stimulation Indices (SI) are also calculated by dividing specific proliferation by background. For these assays, a response with a $\triangle \mathrm{PF}$ value of at least $1.0 \%$ with an SI of $\geq 2.0$ is considered a positive response, based on our initial standardization experiments [18]. It is also important to note that the numbers indicated in Figure 1 represent the proportion of gated cells in the proliferating fraction (PF) on the day of analysis (in this case, day 7 of culture). As evident from the CFSE staining pattern (Figure 1), the vast majority of cells have undergone 4-6 divisions in this time frame. Thus, the PF values do not directly represent the original precursor frequency of antigen-specific $\mathrm{T}$ cells. However, these values are proportional to the precursor frequency and, by gating on individual divisions, it is possible to calculate this value [54].

In this patient (Figure 1), robust $\mathrm{T}$ cell proliferative responses were detected to MBP, PLPmix 2 and OMGP, whereas there were no responses to MAG-mix 1 (compared with background; i.e., no antigen). Importantly, responses in MS patients were not restricted to the CD4+ T cell subset. Significant CD8+ T cell proliferative responses were observed against several antigens (in this case, to MBP, PLP-2, MOBP and OMGP) with or without concomitant CD4 responses. After evaluating several MS patients, we observed a widespread CD8+ T cell reactivity to multiple CNS autoantigens [18]. Immunophenotyping capabilities offered by flow cytometry were crucial in identifying CD8+ T cell responses to neuroantigens as it was impossible to identify the proliferating cellular fractions in traditional proliferation assays using thymidine labeling.

Of diagnostic relevance, while autoreactive $\mathrm{CD} 4+\mathrm{T}$ cell responses were similar in their specificity between MS patients and healthy control subjects, some statistical differences were observed in the distribution of autoreactive CD8+ T cell responses between the different subject groups. Overall, a higher prevalence of autoreactive CD8+ T cell responses was noted in RRMS patients. In addition, compared to healthy subjects, a higher proportion of RRMS patients showed CD8+ T cell responses to MOBP, which is a known encephalitogenic target protein $[55,56]$. These results suggest that differences may exist in the specificity, prevalence and functional role of CNS-specific CD8+ T cell responses in different subtypes of MS. Replicate experiments performed over several days utilizing frozen PBMC specimens obtained from MS patients showed that this assay has a good reproducibility (Table 1).

Once we standardized the CFSE assay to reproducibly detect proliferation, we also evaluated it for its ability to detect truly antigen-specific responses (versus bystander proliferation), through the following approaches: 
First, using MHC/HLA blockade, we could show that the CFSE assay system detects HLA-restricted CD8+ and CD4+ T cell responses.

Further, to test the specificity of the assay, we performed single-cell sorting of antigenreactive $\mathrm{CD} 4+$ and $\mathrm{CD} 8+\mathrm{T}$ cells to generate $\mathrm{T}$ cell clones and lines for evaluation of their antigen specificity. Such clones and lines were expanded using non-specific mitogenic stimuli (phytohemagglutinin/PHA), followed by testing of their antigenic specificity. These experiments showed that the vast majority of the sorted cells were indeed specific for their original antigen. These results confirmed that the flow cytometric readout of a short-term (7day) CFSE-based assay is able to detect and quantify antigen-specific CD4+ and CD8+ T cells in a one-step culture system. Thus, this technology can be effectively utilized to evaluate the status of CNS-specific reactivity in a given individual.

\section{Functional flow cytometric characterization of antigen-specific $\mathrm{T}$ cell responses}

One method for determining the functional state of $\mathrm{T}$ cells is cytokine flow cytometry, wherein intracellular cytokines are directly detected by fluorescent staining. While this methodology is widely in use for the evaluation of antiviral $\mathrm{T}$ cell responses, it has met with less success in the case of autoreactive $\mathrm{T}$ cells, likely owing to their low precursor frequency and low avidity. Thus, an in vitro expansion step is required to reproducibly detect and phenotype autoreactive $\mathrm{T}$ cell responses. The CFSE-based assay system can be productively combined with intracellular cytokine staining.

As discussed earlier, although healthy subjects and MS patients have similar magnitudes of CNS-specific $\mathrm{T}$ cell responses, these responses are qualitatively distinct in these groups of individuals. Autoreactive T cell responses in MS patients are thought to be at a more differentiated memory/effector state, compared to those in healthy subjects $[5,22,24,57,58]$. Using this information, we initially focused on the four-color format, and the following markers CFSE/ CD45RO/CD4/CD8 in Figure 2.

This uses CD45RO as a marker of the "memory phenotype". This marker, used singly, is not perfect, as memory/effector cells may lose CD45RO expression during differentiation.

However, it can be safely said that mature $\mathrm{T}$ cells that do express CD45RO are memory/ effector cells. In this specific experiment, we modified the assay further by using low doses of antigen ( $1 \mathrm{mg} / \mathrm{ml}$ per peptide) and adding IL-7 to the culture. This system has been shown to promote the expansion of effector/memory $\mathrm{T}$ cells with potentially higher avidity, which characterizes the response in MS patients [23,24]. PBMC from untreated RRMS patients or healthy subjects were used in the CFSE-based assay. Mixes of serial overlapping 15-mer peptides representing MBP and PLP as the CNS antigens were used. Interestingly, the use of merely one marker and 2 CNS antigens allowed us to discriminate between RRMS and healthy subjects. Thus, a significantly higher proportion of neuroantigen-specific CD4+ T cells were CD45RO+ in MS patients (Figure 2). Each dot in the graph represents a positive response to either MBP or PLP from each subject tested. Importantly, the two "false positive" responses from the healthy subjects (two black dots above the cutoff line in the left panel) represent a single subject's response to 2 different myelin antigens. 
Thus, 9 of 10 healthy subjects were classified correctly by this cutoff. Similarly, from the 10 MS patients, 1 subject had 2 responses that fell below the cutoff for CD45RO expression ("false negative"), whereas 1 subject had 1 response above the cutoff and 1 below (and would have thus been classified correctly, based on the high CD45RO-expressing response). Thus, 9 of 10 MS patients would be classified correctly, indicating a sensitivity of $\sim 88-90 \%$ and a specificity of $90 \%$, based simply on a single parameter (CD45RO expression on responding CD4 cells) and a small number of antigens (MBP and PLP). These are very promising numbers for a practical and clinically relevant flow cytometry based testing procedure.

The addition of more antigens and markers will undoubtedly improve the sensitivity and specificity of this testing procedure. For example, it is entirely possible that the CD45RO (-) cells from the MS patients in fact represented terminally differentiated effector cells that are known to switch back to a CD45RA+ phenotype. By simply adding one more marker (e.g, $\mathrm{CD} 27)$, it is possible to differentiate the true CD45RO (-) responses that are naïve (CD27+) versus those that are effector/memory (CD27neg). Thus, the addition of more markers will minimize the occurrence of false negative results and the addition of more CNS antigens for the stimulation of these cultures will ensure the visualization of at least one positive response. As an example, we evaluated the combination of CD27 and CD45RO on responding (CNS-specific) CD4+ T cells (Figure 3). As shown in Figure 3, the addition of the CD27/CD45RO combination indeed enhanced the discriminatory ability on this test. While MS patients showed significantly higher numbers of cells in the CD27-/CD45RO+ fraction (Figure 3), healthy subjects responded with CD27+/CD45RO- or CD27+/CD45RO+ $\mathrm{T}$ cells. It is therefore clear that considerable power would be added to this assay system by being able to evaluate a greater number of parameters in the same culture tube.

Similar tests could be carried out with CD8+ T cells. First, as an important marker for CD8+ $\mathrm{T}$ cell differentiation, we have also used the CFSE/CD28/CD4/CD8 combination and seen that a very high proportion of CNS-specific CD8+ T cells are CD28neg in MS patients, suggesting a state of chronic antigenic exposure (Figure 4). Second, during CD8+ T cell differentiation, CD28-/CD8+ T cells also tend to exhibit a CD57+ phenotype, as an indicator of in vivo terminal effector differentiation. We thus used a combination of CD28 and CD57, along with either $\mathrm{CD} 8$ or $\mathrm{CD} 4$, to test whether these markers would enhance immunologic discrimination between MS and healthy subjects. Our recent data demonstrates that the evaluation of these 2 markers on CD8+ T cell responses can robustly discriminate responses of MS patients from those of healthy subjects $[59,60]$.

Importantly, a combination of CD4 and CD8 parameters could also differentiate MS from other neurologic diseases (Table 2). We recruited a preliminary cohort of 6 patients with diverse, non-MS, chronic neuroinflammatory disease ( 2 with myasthenia gravis, 2 with Devic's disease and 1 with neurosarcoidosis). Only 3 of these 5 patients could be distinguished from MS based simply on the CD4 criterion alone that less than $65 \%$ of the responding cells exhibit a CD45RO (+) phenotype (denoted by check marks in the table). Importantly, 4 of 5 could be distinguished based on the CD8 criterion alone that less than $25 \%$ of the responding cells exhibit a CD28 (-) phenotype. Once the CD4 and CD8 criteria were combined, 5 of 5 patients could be distinguished. 
Thus, it is evident from these simple 4-color combinations that the one-step CFSE-based flow cytometry assay system can be modified for use in the immunologic discrimination and monitoring of MS patients.

\section{Assessment of suppressive potential of T cells using flow cytometry}

MS has been associated with defects in the regulatory arm of the immune system. Importantly, flow cytometry data from several labs have revealed that the most pronounced defect during MS relapse appears to be in the regulatory cell compartments as several populations of regulatory cells are shown to be defective during MS relapse including:

1) Reduced percentages of $\mathrm{CD} 4+\mathrm{CD} 25+\mathrm{FoxP} 3+$ cells and reduced expression of FoxP3 in the blood during relapse [61]

2) Reduction in the suppressive potential of CD4+CD25+ T cells in relapsing patients under inflammatory conditions [61]

3) Increased percentages of PD1-Treg cells in the blood during remission as compared to relapse (62) and

4) Reduction in IL-10 producing Bregs during relapse (63). We have gone a step further and have developed and adapted a sensitive flow cytometry based suppression assay to measure the suppressive ability of both CD4+ and CD8+ T cells obtained from MS patients (Figure 5A).

This suppression assay, conducted on carefully recruited treatment-naïve patients before administration of steroids, has identified novel features of immune regulation during an MS relapse:

1) A strikingly reduced suppressive potential of CNS-specific CD8+ Tregs during relapse as compared to remission [21]

2) A relative resistance of CD4 effector cells to CD8 suppression [16]

3) Lack of terminally differentiated CNS-specific CD8 T cells during relapse, with concurrent deficit in perforin and granzyme $\mathrm{B}$ expression. The assay measures the proliferation and activation of CFSE-stained CD4+CD25- responder T-cells in response to either a mitogenic stimuli such as CD3 or specific antigens such as myelin antigens. Putative suppressor cells were stained with a tracker dye, CMPTX [29], allowing their exclusion from the analysis. CMTPX-stained $\mathrm{CD} 4+\mathrm{CD} 25+$ (positive control), CD8+ or CD4+CD25-(negative control) T-cells were added in increasing numbers and their effect on responder proliferation was quantified, by normalizing to the RI of CD4+CD25- T-cells (treated as $100 \%$ proliferation or $0 \%$ suppression). Using anti-CD3 stimulation, we observed consistent suppressive activity in the CD4+CD25+ and CD8+ populations, while CMTPX-stained CD4+CD25- T-cells did not significantly dampen pan-stimulated CD4+CD25- T-cells (negative control) [21]. Interestingly, non-fractionated CD8+ T-cells showed greater suppressive capacity than CD4+CD25+ T-cells, a fraction known to contain regulatory Tcells [21]. We then sought to evaluate the suppressive ability of CD8+ T-cells in 
cultures stimulated with specific antigens by conducting suppression assays using a panel of CNS and control antigens. Positive CD4 T-cell responses to specific antigens were selected and suppression was quantified. Addition of increasing numbers of CD8+ T-cells suppressed the proliferation and activation of neuroantigen-stimulated responses, in contrast to foreign-antigen-stimulated responses [21]. As shown in Figure 5, this assay for the first time showed that neuroantigen-specific CD8+ T-cells obtained ex vivo possessed immune suppressive ability, whereas foreign antigen-specific ones did not show consistent suppression. The potential of implementing this flow cytometry based suppression assay as a routine for monitoring immune system of MS patients comes from the fact that neuroantigen specific suppressive ability of CD8 T cell is lacking during MS exacerbation [21]. Interestingly, this suppressor ability is restored in longitudinally followed quiescent MS samples. Whether CNSspecific regulatory ability is key in the mechanism of MS clinical phase changes remains an open question, and flow cytometry will be an indispensable tool for addressing this critical knowledge in MS.

\section{Therapy monitoring by flow cytometry}

While immunomodulatory therapies are widely employed for the treatment of MS patients, monitoring of the immune system is not part of standard patient care. In fact, there is no requirement to confirm immune alteration before one treats a patient with the immune modifiers.

Flow cytometry becomes an indispensable tool to monitor the immunologic effects of the drugs in MS patients. Importantly these changes might eventually be predictive of the clinical effects and the therapy outcome in MS patients. One of the best examples of implementing FACS for monitoring the immune system after therapy initiation comes from our own studies with MS patients on Copaxone therapy.

Using CFSE based proliferation assays that can be read by flow cytometry, we have provided the first direct evidence that GA induces not only CD4+, but also CD8+ T cell responses [27]. To our surprise, we found that there was a robust CD4+ $\mathrm{T}$ cell response to GA even in the untreated MS patient. In addition, there was a detectable GA-specific CD8+ proliferative response in the untreated MS patient. Importantly, distinct from the effect on the CD4+ response, GA therapy resulted in the induction and upregulation of the CD8+ response (Figure 6A). These studies provided the first direct evidence of the existence of a CD8+ proliferative response to GA, which is differentially upregulated following therapy [19]. Using this FACS based assay, when these responses were followed for a period of 11 months, the overall pattern of CD4+ GA-specific responses was a transient increase at the 3month time point, followed by a gradual decline. This pattern was seen in 4 of 5 patients. In contrast, GA-specific CD8+ T cell responses significantly increased following GA therapy [19]. Therefore, the potential of immunophenotyping by FACS revealed that the major effect of GA therapy was an upregulation of GA-reactive CD8+ T cell responses. Importantly, such temporal variations in GA-reactive CD4+ or CD8+ T cell responses were not observed in untreated MS patients or in healthy individuals. Flow cytometry based 
proliferation assay enabled us to uncover a novel mechanism through which this FDAapproved drug may mediate its immunologic effects. The approach for delineating antigenspecific $\mathrm{T}$ cell responses is a fairly short term assay (as compared to studying established long term $\mathrm{T}$ cell lines), therefore, it is possible to detect such responses with greater sensitivity and without growth-related bias due to long term culture.

In the next set of experiments and as shown in Figure 6B, we performed the flow cytometry based suppression assay described above and discovered that GA-reactive CD8+ T cells possess suppressor ability $[19,64]$. Of clinical relevance, GA induced suppressive CD8 phenotype can be tracked overtime in MS patients to potentially predict eventual immune response and, by corollary, eventual clinical responsiveness or lack thereof. In fact, our flow cytometry based assay system has shown that GA specific suppressive CD8 T cell phenotype can be detected as early as $12 \mathrm{~h}$ after therapy initiation [20]. This time point was also associated with reversal of CD4/CD8 T cell ratio and an increase in EM CD8+ T cells in the blood of MS patients initiating GA therapy, as revealed by immunophenotyping using flow cytometry. Our proliferation and suppression assay provides a minimally invasive and a powerful tool to measure CD8 suppressor ability over time in MS patients on GA therapy, information which could potentially be used to determine clinical responsiveness to GA in MS patients.

Our studies demonstrate how FACS can be used, beyond immunophenotyping, to uncover clinically relevant immunological changes in the peripheral immune system of MS patients. Incorporating such functional assays for the disease management might also facilitate understanding of clinically relevant therapeutic changes in the immune system of MS patients taking immunomodulatory treatments.

\section{Acknowledgements}

This work was supported, in part, by grant awards K24 AI079272, R01AI065463 and R01AI053439 (to NJK) from the NIH and National MS Society. We thank Drs. Elliot Frohman, Benjamin Greenberg and E. Torage Shivapour as well as the staff and patients of the UT Southwestern Medical Center and University of Iowa MS Clinics for their support of our studies.

We thank all the people involved in developing these assays over the years, particularly Nathan York, Vinodh Pillai, Ethan Baughman, Deepani Tennakoon and Imran Mohiuddin, among others.

\section{References}

1. Martin R, McFarland HF, McFarlin DE. Immunological aspects of demyelinating diseases. Annu Rev Immunol. 1992; 10:153-187. [PubMed: 1375472]

2. Sadovnick AD, Ebers GC. Epidemiology of multiple sclerosis: a critical overview. Can J Neurol Sci. 1993; 20:17-29. [PubMed: 8467424]

3. Martyn CN, Gale CR. The epidemiology of multiple sclerosis. Acta Neurol Scand Suppl. 1997; 169:3-7. [PubMed: 9174634]

4. Arnason BG. Relevance of experimental allergic encephalomyelitis to multiple sclerosis. Neurol Clin. 1983; 1:765-782. [PubMed: 6209540]

5. Lovett-Racke AE, Trotter JL, Lauber J, Perrin PJ, June CH, et al. Decreased dependence of myelin basic protein-reactive T cells on CD28-mediated costimulation in multiple sclerosis patients. A marker of activated/memory T cells. J Clin Invest. 1998; 101:725-730. [PubMed: 9466965] 
6. Martin R, Jaraquemada D, Flerlage M, Richert J, Whitaker J, et al. Fine specificity and HLA restriction of myelin basic protein-specific cytotoxic $\mathrm{T}$ cell lines from multiple sclerosis patients and healthy individuals. J Immunol. 1990; 145:540-548. [PubMed: 1694881]

7. Ota K, Matsui M, Milford EL, Mackin GA, Weiner HL, et al. T-cell recognition of an immunodominant myelin basic protein epitope in multiple sclerosis. Nature. 1990; 346:183-187. [PubMed: 1694970]

8. Jingwu Z, Medaer R, Hashim GA, Chin Y, van den Berg-Loonen E, et al. Myelin basic proteinspecific T lymphocytes in multiple sclerosis and controls: precursor frequency, fine specificity, and cytotoxicity. Ann Neurol. 1992; 32:330-338. [PubMed: 1384421]

9. Joshi N, Usuku K, Hauser SL. The T-cell response to myelin basic protein in familial multiple sclerosis: diversity of fine specificity, restricting elements, and T- cell receptor usage. Ann Neurol. 1993; 34:385-393. [PubMed: 7689820]

10. Goebels N, Hofstetter H, Schmidt S, Brunner C, Wekerle H. Repertoire dynamics of autoreactive T cells in multiple sclerosis patients and healthy subjects: epitope spreading versus clonal persistence. Brain. 2000; 123:508-518. [PubMed: 10686174]

11. Poser CM, Brinar VV. Diagnostic criteria for multiple sclerosis. Clin Neurol Neurosurg. 2001; 103:1-11. [PubMed: 11311469]

12. Poser CM, Paty DW, Scheinberg L, McDonald WI, Davis FA, et al. New diagnostic criteria for multiple sclerosis: guidelines for research protocols. Ann Neurol. 1983; 13:227-231. [PubMed: 6847134]

13. Polman CH, Reingold SC, Banwell B, Clanet M, Cohen JA, et al. Diagnostic criteria for multiple sclerosis: 2010 revisions to the McDonald criteria. Ann Neurol. 2011; 69:292-302. [PubMed: 21387374]

14. Sinha S, Itani FR, Karandikar NJ. Immune regulation of multiple sclerosis by CD8+ T cells. Immunologic research. 2014; 59:254-265. [PubMed: 24845461]

15. Ortega SB, Kashi VP, Tyler AF, Cunnusamy K, Mendoza JP, et al. The disease-ameliorating function of autoregulatory CD8 T cells is mediated by targeting of encephalitogenic CD4 T cells in experimental autoimmune encephalomyelitis. J Immunol. 2013; 191:117-126. [PubMed: 23733879]

16. Cunnusamy K, Baughman EJ, Franco J, Ortega SB, Sinha S, et al. Disease exacerbation of multiple sclerosis is characterized by loss of terminally differentiated autoregulatory CD8+ T cells. Clin Immunol. 2014; 152:115-126. [PubMed: 24657764]

17. Kashi VP, Ortega SB, Karandikar NJ. Neuroantigen-specific autoregulatory CD8+ T cells inhibit autoimmune demyelination through modulation of dendritic cell function. PLoS One. 2014; 9:e105763. [PubMed: 25144738]

18. Crawford MP, Yan SX, Ortega SB, Mehta RS, Hewitt RE, et al. High Prevalence of Autoreactive Neuroantigen-Specific CD8+ T Cells in Multiple Sclerosis Revealed by Novel Flow Cytometric Assay. Blood. 2004; 103:4222-4231. [PubMed: 14976054]

19. Karandikar NJ, Crawford MP, Yan X, Ratts RB, Brenchley JM, et al. Glatiramer acetate (Copaxone) therapy induces CD8(+) T cell responses in patients with multiple sclerosis. J Clin Invest. 2002; 109:641-649. [PubMed: 11877472]

20. Ayers CL, Mendoza JP, Sinha S, Cunnusamy K, Greenberg BM, et al. Modulation of immune function occurs within hours of therapy initiation for multiple sclerosis. Clin Immunol. 2013; 147:105-119. [PubMed: 23578552]

21. Baughman EJ, Mendoza JP, Ortega SB, Ayers CL, Greenberg BM, et al. Neuroantigen-specific $\mathrm{CD} 8+$ regulatory T-cell function is deficient during acute exacerbation of multiple sclerosis. $\mathrm{J}$ Autoimmun. 2011; 36:115-124. [PubMed: 21257291]

22. Allegretta M, Nicklas JA, Sriram S, Albertini RJ. T cells responsive to myelin basic protein in patients with multiple sclerosis. Science. 1990; 247:718-721. [PubMed: 1689076]

23. Bielekova B, Sung MH, Kadom N, Simon R, McFarland H, et al. Expansion and functional relevance of high-avidity myelin-specific CD4+ T cells in multiple sclerosis. J Immunol. 2004; 172:3893-3904. [PubMed: 15004197] 
24. Bielekova B, Muraro PA, Golestaneh L, Pascal J, McFarland HF, et al. Preferential expansion of autoreactive T lymphocytes from the memory T-cell pool by IL-7. J Neuroimmunol. 1999; 100:115-123. [PubMed: 10695722]

25. Altman JD, Moss PAH, Goulder PJR, Barouch DH, McHeyzer-Williams MG, et al. Phenotypic analysis of antigen-specific T lymphocytes. Science. 1996; 274:94-96. [PubMed: 8810254]

26. Callan MF, Tan L, Annels N, Ogg GS, Wilson JD, et al. Direct visualization of antigen-specific CD8+ T cells during the primary immune response to Epstein-Barr virus In vivo. J Exp Med. 1998; 187:1395-1402. [PubMed: 9565632]

27. Betts MR, Casazza JP, Patterson BA, Waldrop S, Trigona W, et al. Putative immunodominant human immunodeficiency virus-specific $\mathrm{CD} 8(+) \mathrm{T}$-cell responses cannot be predicted by major histocompatibility complex class I haplotype. J Virol. 2000; 74:9144-9151. [PubMed: 10982361]

28. Helms T, Boehm BO, Asaad RJ, Trezza RP, Lehmann PV, et al. Direct visualization of cytokineproducing recall antigen-specific CD4 memory $\mathrm{T}$ cells in healthy individuals and HIV patients. $\mathrm{J}$ Immunol. 2000; 164:3723-3732. [PubMed: 10725731]

29. Heeger PS, Valujskikh A, Lehmann PV. Comprehensive assessment of determinant specificity, frequency, and cytokine signature of the primed CD8 cell repertoire induced by a minor transplantation antigen. J Immunol. 2000; 165:1278-1284. [PubMed: 10903727]

30. Pelfrey CM, Rudick RA, Cotleur AC, Lee JC, Tary-Lehmann M, et al. Quantification of selfrecognition in multiple sclerosis by single-cell analysis of cytokine production. J Immunol. 2000; 165:1641-1651. [PubMed: 10903775]

31. Pitcher CJ, Quittner C, Peterson DM, Connors M, Koup RA, et al. HIV-1-specific CD4+ T cells are detectable in most individuals with active HIV-1 infection, but decline with prolonged viral suppression. Nat Med. 1999; 5:518-525. [PubMed: 10229228]

32. Kern F, Surel IP, Brock C, Freistedt B, Radtke H, et al. T-cell epitope mapping by flow cytometry. Nat Med. 1998; 4:975-978. [PubMed: 9701254]

33. Murali-Krishna K, Altman JD, Suresh M, Sourdive DJ, Zajac AJ, et al. Counting antigen-specific CD8 T cells: a reevaluation of bystander activation during viral infection. Immunity. 1998; 8:177187. [PubMed: 9491999]

34. Navikas V, Link H. Review: cytokines and the pathogenesis of multiple sclerosis. J Neurosci Res. 1996; 45:322-333. [PubMed: 8872892]

35. Bever CT, Panitch HS Jr, Levy HB, McFarlin DE, Johnson KP. Gamma-interferon induction in patients with chronic progressive MS. Neurology. 1991; 41:1124-1127. [PubMed: 1829795]

36. Hofman FM, Hinton DR, Johnson K, Merrill JE. Tumor necrosis factor identified in multiple sclerosis brain. J Exp Med. 1989; 170:607-612. [PubMed: 2754393]

37. Vartanian T, Li Y, Zhao M, Stefansson K. Interferon-gamma-induced oligodendrocyte cell death: implications for the pathogenesis of multiple sclerosis. Mol Med. 1995; 1:732-743. [PubMed: 8612196]

38. Windhagen A, Anderson DE, Carrizosa A, Balashov K, Weiner HL, et al. Cytokine secretion of myelin basic protein reactive T cells in patients with multiple sclerosis. J Neuroimmunol. 1998; 91:1-9. [PubMed: 9846813]

39. Martin R, Ruddle NH, Reingold S, Hafler DA. T helper cell differentiation in multiple sclerosis and autoimmunity. Immunol Today. 1998; 19:495-498. [PubMed: 9818541]

40. Targoni OS, Baus J, Hofstetter HH, Hesse MD, Karulin AY, et al. Frequencies of neuroantigenspecific $\mathrm{T}$ cells in the central nervous system versus the immune periphery during the course of experimental allergic encephalomyelitis. J Immunol. 2001; 166:4757-4764. [PubMed: 11254738]

41. Hellings N, Baree M, Verhoeven C, D'Hooghe MB, Medaer R, et al. T-cell reactivity to multiple myelin antigens in multiple sclerosis patients and healthy controls. J Neurosci Res. 2001; 63:290302. [PubMed: 11170179]

42. Farina C, Then Bergh F, Albrecht H, Meinl E, Yassouridis A, et al. Treatment of multiple sclerosis with Copaxone (COP): Elispot assay detects COP-induced interleukin-4 and interferon-gamma response in blood cells. Brain. 2001; 124:705-719. [PubMed: 11287371]

43. Wallstrom E, Khademi M, Andersson M, Weissert R, Linington C, et al. Increased reactivity to myelin oligodendrocyte glycoprotein peptides and epitope mapping in HLA DR2(15)+ multiple sclerosis. Eur J Immunol. 1998; 28:3329-3335. [PubMed: 9808202] 
44. Waldrop SL, Pitcher CJ, Peterson DM, Maino VC, Picker LJ. Determination of antigen-specific memory/effector CD4+ T cell frequencies by flow cytometry: evidence for a novel, antigenspecific homeostatic mechanism in HIV-associated immunodeficiency. J Clin Invest. 1997; 99:1739-1750. [PubMed: 9120019]

45. Waldrop SL, Davis KA, Maino VC, Picker LJ. Normal human CD4+ memory T cells display broad heterogeneity in their activation threshold for cytokine synthesis. J Immunol. 1998; 161:5284-5295. [PubMed: 9820501]

46. Picker LJ, Singh MK, Zdraveski Z, Treer JR, Waldrop SL, et al. Direct demonstration of cytokine synthesis heterogeneity among human memory/effector T cells by flow cytometry. Blood. 1995; 86:1408-1419. [PubMed: 7632949]

47. Lyons AB, Parish CR. Determination of lymphocyte division by flow cytometry. J Immunol Methods. 1994; 171:131-137. [PubMed: 8176234]

48. Lyons AB. Divided we stand: tracking cell proliferation with carboxyfluorescein diacetate succinimidyl ester. Immunol Cell Biol. 1999; 77:509-515. [PubMed: 10571671]

49. Lyons AB. Analysing cell division in vivo and in vitro using flow cytometric measurement of CFSE dye dilution. J Immunol Methods. 2000; 243:147-154. [PubMed: 10986412]

50. Fulcher D, Wong S. Carboxyfluorescein succinimidyl ester-based proliferative assays for assessment of T cell function in the diagnostic laboratory. Immunol Cell Biol. 1999; 77:559-564. [PubMed: 10571678]

51. Mintern J, Li M, Davey GM, Blanas E, Kurts C, Carbone FR, et al. The use of carboxyfluorescein diacetate succinimidyl ester to determine the site, duration and cell type responsible for antigen presentation in vivo. Immunol Cell Biol. 1999; 77:539-543. [PubMed: 10571675]

52. Sathiyaseelan T, Baldwin CL. Evaluation of cell replication by bovine T cells in polyclonally activated cultures using carboxyfluorescein succinimidyl ester (CFSE) loading and flow cytometric analysis. Res Vet Sci. 2000; 69:275-281. [PubMed: 11124100]

53. Brenchley JM, Karandikar NJ, Betts MR, Ambrozak DR, et al. Expression of CD57 defines replicative senescence and antigen-induced apoptotic death of CD8+ T cells. Blood. 2003; 101:2711-2720. [PubMed: 12433688]

54. Parish, CR.; Warren, HS. Use of intracellular fluorescent dye CFSE to monitor lymphocyte migration and proliferation. John Wiley \& Sons, Inc.; 2001.

55. Kaye JF, Kerlero de Rosbo N, Mendel I, Flechter S, Hoffman M, et al. The central nervous systemspecific myelin oligodendrocytic basic protein (MOBP) is encephalitogenic and a potential target antigen in multiple sclerosis (MS). J Neuroimmunol. 2000; 102:189-198. [PubMed: 10636488]

56. Holz A, Bielekova B, Martin R, Oldstone MB. Myelin-associated oligodendrocytic basic protein: identification of an encephalitogenic epitope and association with multiple sclerosis. J Immunol. 2000; 164:1103-1109. [PubMed: 10623862]

57. Zhang J, Markovic-Plese S, Lacet B, Raus J, Weiner HL, et al. Increased frequency of interleukin 2-responsive T cells specific for myelin basic protein and proteolipid protein in peripheral blood and cerebrospinal fluid of patients with multiple sclerosis. J Exp Med. 1994; 179:973-984. [PubMed: 7509366]

58. Trotter JL, Damico CA, Cross AH, Pelfrey CM, Karr RW, et al. HPRT mutant T-cell lines from multiple sclerosis patients recognize myelin proteolipid protein peptides. J Neuroimmunol. 1997; 75:95-103. [PubMed: 9143242]

59. Ratts RB, Lovett-Racke AE, Choy J, Northrop SC, Hussain RZ, et al. CD28-CD57+ T cells predominate in CD8 responses to glatiramer acetate. J Neuroimmunol. 2006; 178:117-129. [PubMed: 16837065]

60. Ratts RB, Karandikar NJ, Hussain RZ, Choy J, Northrop SC, et al. Phenotypic characterization of autoreactive T cells in multiple sclerosis. J Neuroimmunol. 2006; 178:100-110. [PubMed: 16901549]

61. Frisullo G, Nociti V, Iorio R, Patanella AK, Caggiula M, et al. Regulatory T cells fail to suppress CD4T+-bet+ T cells in relapsing multiple sclerosis patients. Immunology. 2009; 127:418-428. [PubMed: 19016907] 
62. Saresella M, Marventano I, Longhi R, Lissoni F, Trabattoni D, et al. CD4+CD25+FoxP3+PD1regulatory $\mathrm{T}$ cells in acute and stable relapsing-remitting multiple sclerosis and their modulation by therapy. FASEB J. 2008; 22:3500-3508. [PubMed: 18587005]

63. Knippenberg S, Peelen E, Smolders J, Thewissen M, Menheere P, et al. Reduction in IL-10 producing B cells (Breg) in multiple sclerosis is accompanied by a reduced naive/memory Breg ratio during a relapse but not in remission. J Neuroimmunol. 2011; 239:80-86. [PubMed: 21940055]

64. Tennakoon DK, Mehta RS, Ortega SB, Bhoj V, Racke MK, et al. Therapeutic induction of regulatory, cytotoxic CD8+ T cells in multiple sclerosis. J Immunol. 2006; 176:7119-7129. [PubMed: 16709875] 


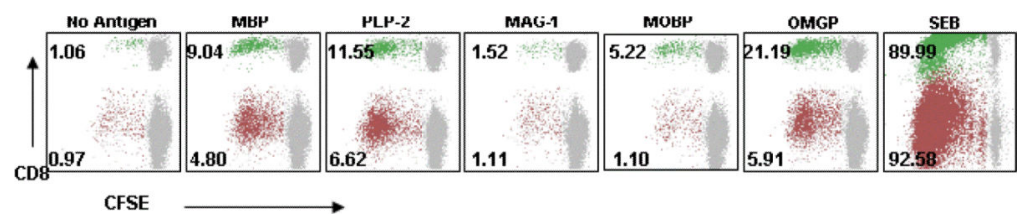

Figure 1.

Antigen-specific proliferation in an MS patient (18) [originally published in Blood 2004, see ref]. PBMC from an MS patient were stained with the green fluorescent dye CFSE. These cells were cultured for 7 days in the presence of the indicated CNS target antigens (pooled overlapping peptides; $10 \mu \mathrm{g} / \mathrm{ml}$ ). Using this strategy, dividing cells can be detected by sequential halving (dilution) of their fluorescence. At the same time, they can be immunophenotyped by staining for cell surface markers or intracellular cytokines. In the figure, CFSE staining is shown on the $\mathrm{X}$-axis and CD8 staining on the Y-axis. The data represent gated CD3+ cells ( $\mathrm{T}$ lymphocytes) further gated for CD8+ and CD4+ T cells. Thus, the CD8- populations in the figure represent gated CD4+ T cells. The gray events represent non-proliferating cells. The numbers indicate the proportion of total CD8+ $\mathrm{T}$ cells (green) or CD4+ T cells (red) that were in the proliferating fraction on day 7 of culture. Background proliferation is demonstrated in the "No Antigen" control. Thus, this patient showed not only CD4+ T cell responses but also CD8+ T cell responses to CNS autoantigens. 

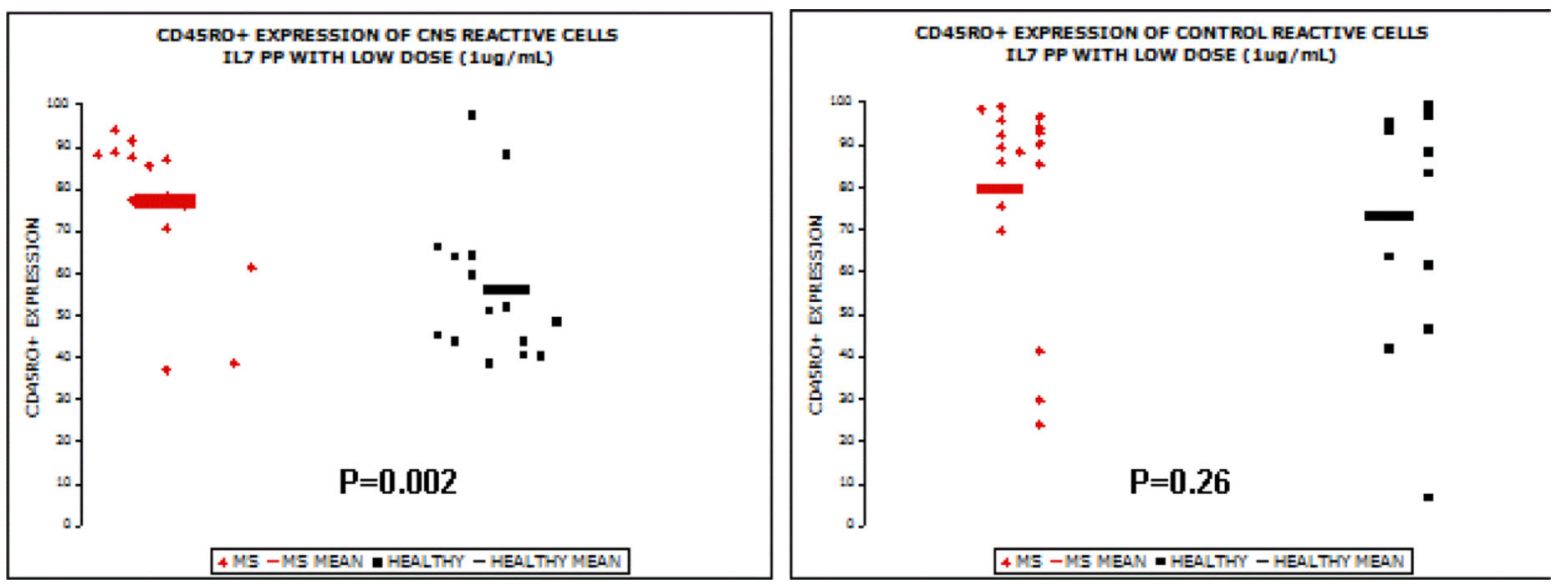

Figure 2.

Neuroantigen specific CD4+ T cells from RRMS patients exhibit a memory phenotype (unpublished data in Tables 1,2 and Figs 2,3,4 generated by M. Crawford, S. Ortega, et al). CFSE based proliferation assay were performed on PBMC from 10 RRMS patients (red) and 10 healthy control subjects (black) to assess the CD4+ T cell responses to CNS autoantigens (MBP and PLP; left panel) and control antigens (TT and SEB; right panel). In this experiment low doses of antigens were used with the addition of Il-7 to the cultures. The positive responses were further evaluated for their CD45RO staining (memory marker). Neuroantigen-specific responses in MS patients showed significantly greater proportion of $\mathrm{CD} 45 \mathrm{RO}+$ cells, compared to those from healthy subjects $(\mathrm{p}=0.002)$, confirming that these responses are at a different state of functional differentiation. The solid horizontal line drawn through the left panel indicates a potential cutoff that may be used for differentiating the two groups. In contrast to CNS antigens, responses to control antigens did not show differences in the two groups. 


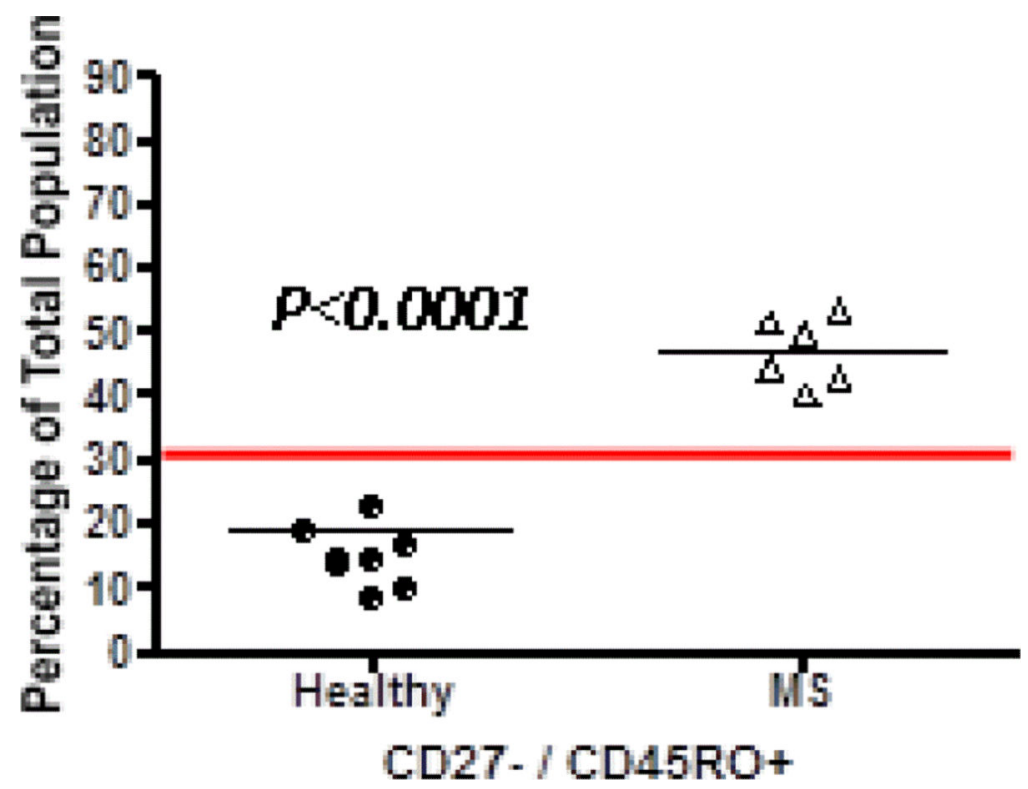

Figure 3.

CD27-/CD45RO+ T cells predominate in the CNS-specific CD4+ T cell response of MS patients. CFSE-based proliferation assays were conducted on PBMC from 5 RRMS patients and 5 healthy subjects. Cells were cultured for 7 days in the presence of MBP, PLP or MOG peptides and were immunophenotyped for CD27 and CD45RO expression. Positive CNSspecific CD4 responses are represented by each dot/triangle. The Y-axis represents the percentage of these responding CD4+ T cells that showed a CD27-/CD45RO+ effector/ memory phenotype. Thus, CNS-specific CD4+ T cell responses from MS patients showed dramatically higher proportion of CD27-/CD45RO+ cells, indicating a more differentiated and effector phenotype, compared to healthy subjects. 


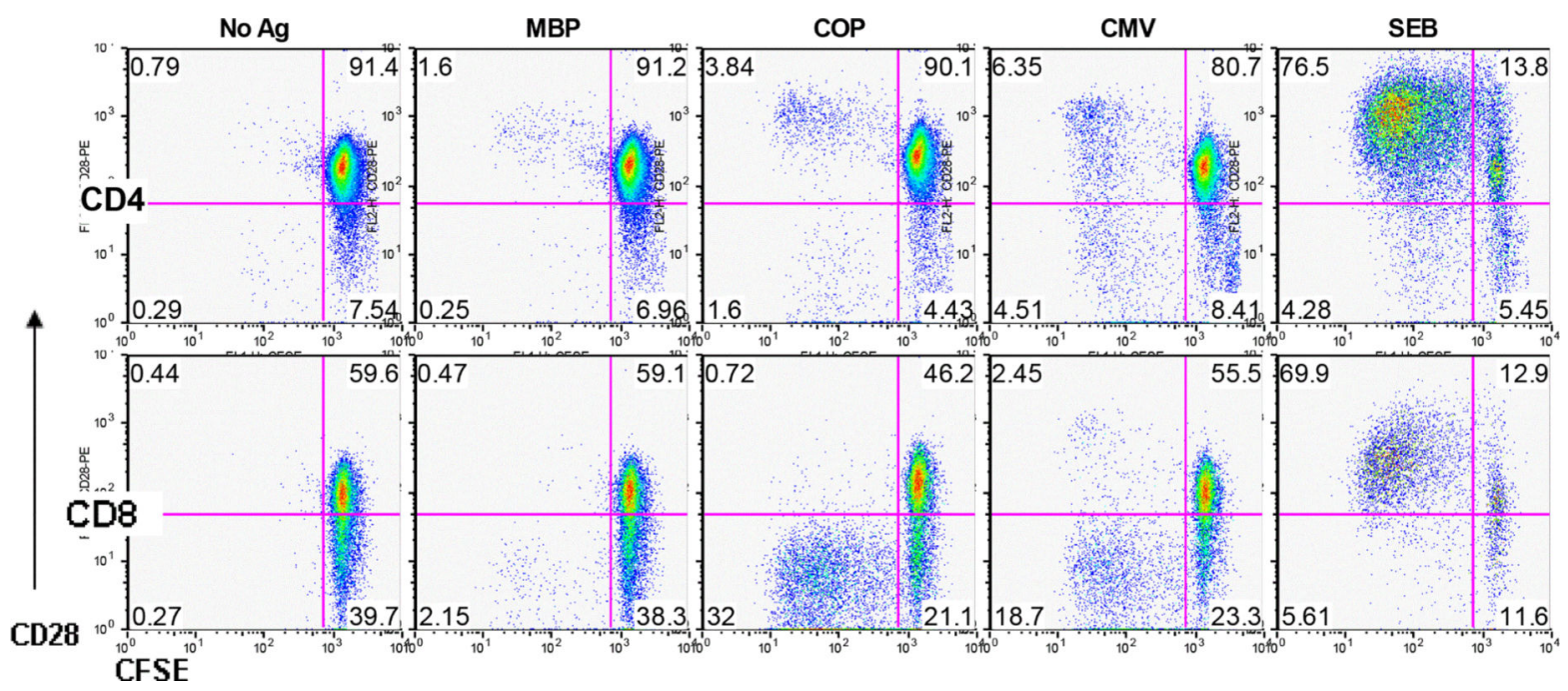

Figure 4.

CD28-/CD8+ T cells contribute to the antigen-specific response. CFSE-based assays were performed to assess CD4+ (top panels) and CD8+ (bottom panels) T cell proliferation to the indicated antigens (MBP, Copaxone, CMV and SEB). CD28 staining was incorporated to evaluate the CD28 phenotype of the responding T cells. As seen in the dot plots, a significant proportion of MBP- and Copaxone-specific CD8+ T cells were CD28-. In contrast, SEB as well as the CD4 response were dominated by CD28+ T cells. 

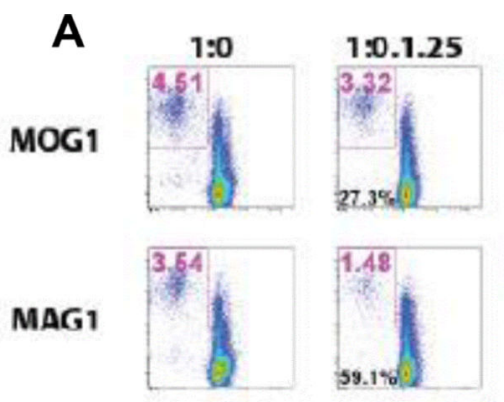

TT
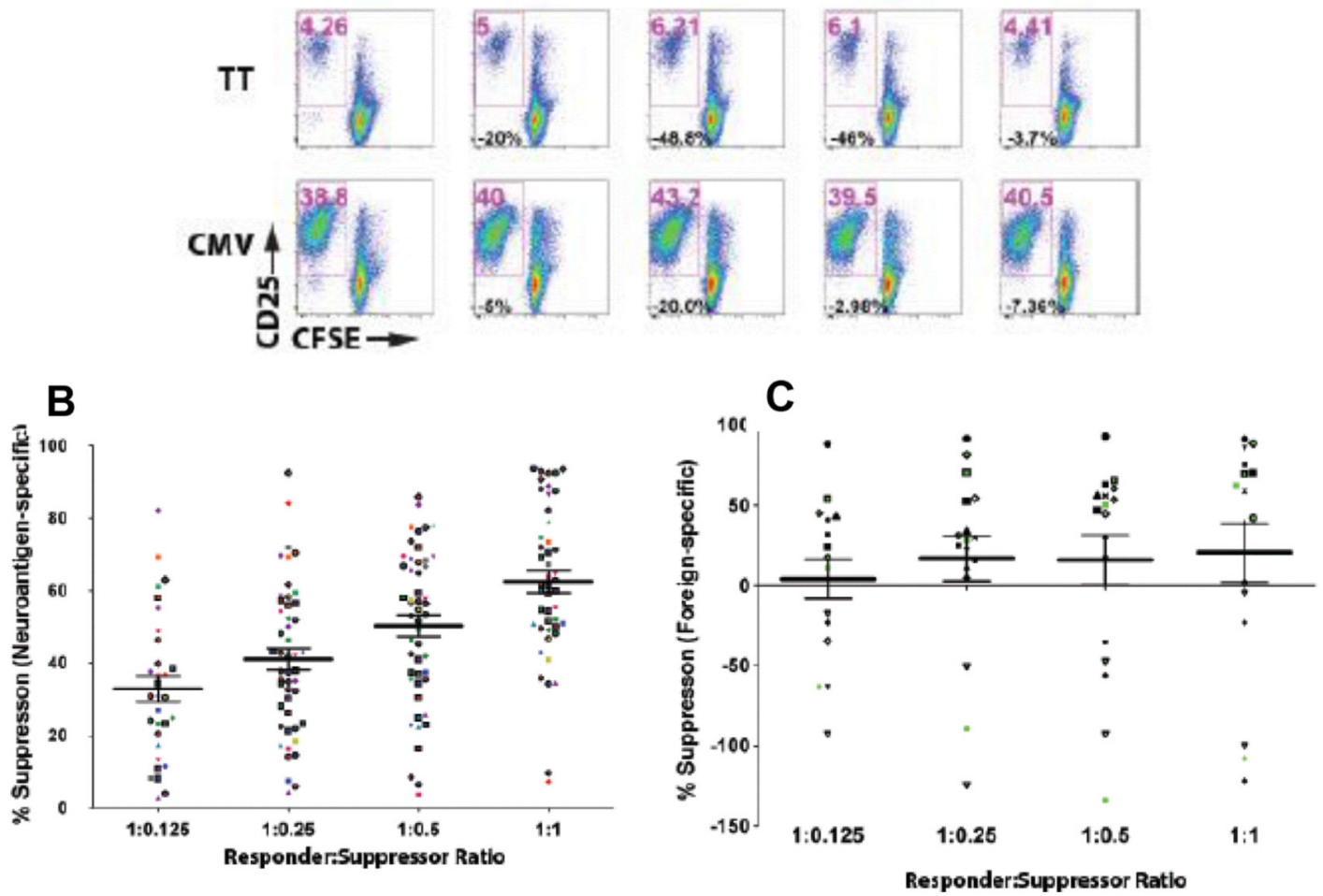
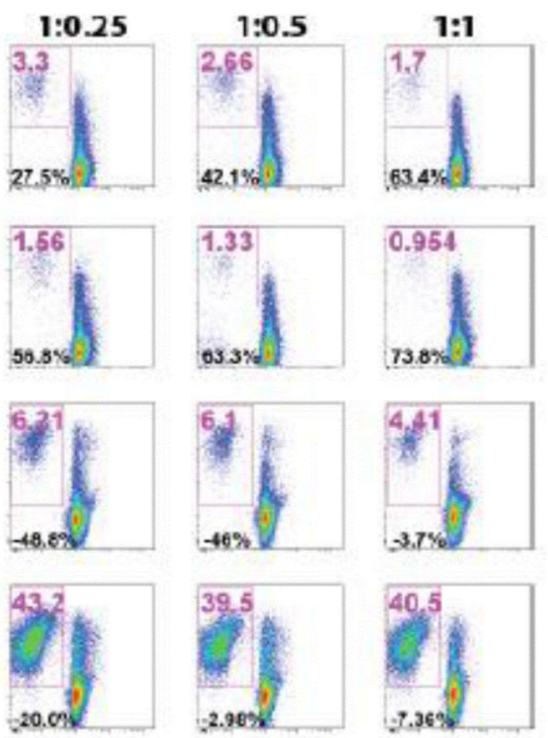

Figure 5.

Neuroantigen-specific CD8+ T-cells suppress CD4+ T-cells [originally published in J. Autoimmunity, see ref (21)]. (A) CFSE-stained healthy ex vivo-purified CD4+CD25- Tcells were used as responders in the presence of neuroantigens (MOG1, MAG1) and foreign antigen (TT, CMV). Representative dotplots from a single subject demonstrate CD8mediated suppression assays in the presence of neuroantigens. Indicated in red at the top of each dotplot is the gated percentage of CD25+/CFSE- low cells (activated and proliferating), representing the "response". Indicated in black in the lower left is the calculated \% suppression, based on normalizing to the neuroantigen-specific response in the absence of suppressors. The left column represents CD4+CD25- responders only, where positive responses were selected to evaluate suppression. The right three columns contain increasing numbers of CMTPX-stained CD8+ T-cells, with \%proliferation and \%suppression indicated. (B, C) Cumulative results are shown from 67 suppression assays. Data points represent neuroantigen- (B) and foreign-antigen- (C) specific \%suppression. Each of 15 subjects is indicated by a different shape. Neuroantigen or foreign antigen used in the suppression assay is indicated by the color legend at right. 


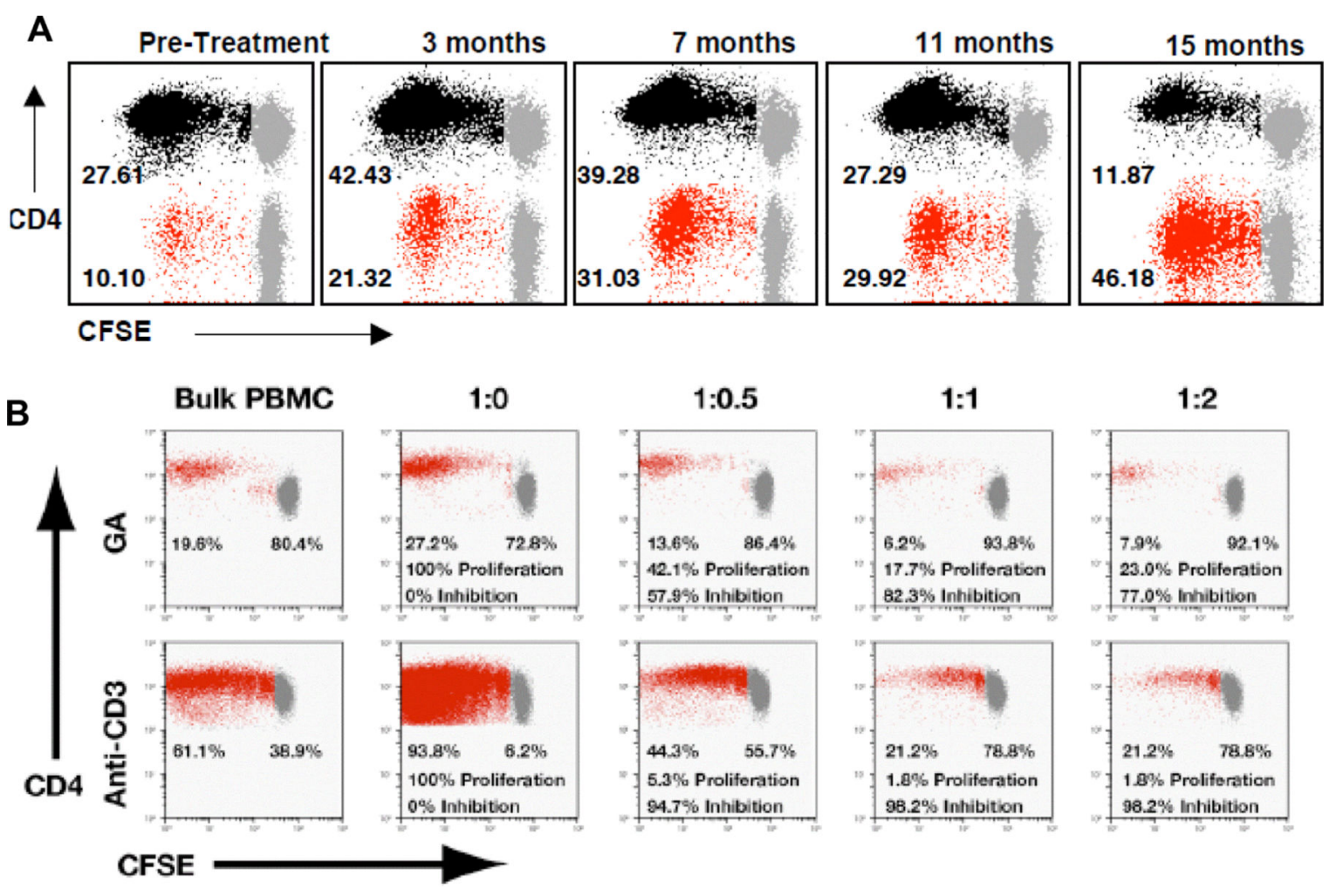

Figure 6.

Differential upregulation of immunosuppressive-GA-specific CD8+ T-cell responses following GA therapy (originally published in J. Clin Invest and J. Immunol; see refs $[19,64])$. Panel A shows CFSE-based proliferation assays conducted on PBMC collected from an RRMS patient before treatment and at the indicated time points after the initiation of daily GA therapy (19). The dot plots indicate gated CD3+ cells (T lymphocytes), further gated for CD4+ and CD8+ events. The numbers represent the proliferating fraction of the gated CD8+ (red) and CD4+ (black) T-cells. The gray events represent non-proliferating cells. Panel B demonstrates a representative suppression assay conducted on a RRMS patient at 7 months of daily GA therapy (64). An aliquot of bulk PBMC was stained with CFSE and used in a CFSE-based proliferation assay. From the remaining PBMC, a purified population of CD8+ T cells was obtained by bead selection $(>95 \%$ pure; $<0.1 \%$ CD4+ T cell contamination). The CD8- depleted fraction was stained with CFSE and used in a proliferation assay with the addition of increasing numbers of unstained, purified CD8+ T cells, with ratios ranging from 1:0 (no CD8+ T cells) through 1:2. The cells were cultured with either no antigen (not shown), GA/Copaxone (top row), anti- CD3 (bottom row) or CMV antigen (Panels B and C). On day 7 of culture, CD4+ T cell proliferation was quantified. CD4 versus CFSE staining is shown in the dotplots. The percentages indicate the fraction of proliferating versus non-proliferating CD4+ T cells. Proliferation (and inhibition) values normalized to the 1:0 ratios are also shown. 


\section{Table 1}

$\mathrm{T}$ cell responses between the different subject groups.

\begin{tabular}{|l|l|l|l|l|l|l|l|}
\hline & & \multicolumn{3}{|l|}{ CD4 Responses } & \multicolumn{3}{l|}{ CD8 Responses } \\
\hline Pt\# & Ag & $\mathbf{\# 1}$ & $\mathbf{\# 2}$ & $\mathbf{\# 3}$ & $\mathbf{\# 1}$ & $\mathbf{\# 2}$ & $\mathbf{\# 3}$ \\
\hline MS2 & Cop-1 & 24.97 & 19.18 & 19.13 & 2.73 & 2.98 & 2.09 \\
\hline & Cop-2 & 18.32 & 21.78 & 26.06 & 1.73 & 2.63 & 3.04 \\
\hline & Cop-3 & 20.25 & 18.62 & 22.20 & 2.54 & 2.34 & 1.89 \\
\hline & TT-1 & 3.59 & 3.71 & 2.71 & 1.62 & 0.84 & 1.09 \\
\hline & TT-2 & 2.72 & 3.19 & 3.20 & 0.94 & 1.63 & 1.75 \\
\hline & TT-3 & 5.01 & 4.47 & 3.78 & 1.25 & 2.01 & 2.00 \\
\hline MS3 & Cop-1 & 20.01 & 22.78 & 21.03 & 5.80 & 5.68 & 6.29 \\
\hline & Cop-2 & 25.00 & 19.63 & 22.63 & 7.58 & 6.82 & 6.79 \\
\hline & Cop-3 & 24.83 & 18.99 & 19.23 & 7.07 & 7.29 & 4.77 \\
\hline & TT-1 & 10.03 & 11.58 & 10.81 & 3.60 & 2.30 & 2.39 \\
\hline & TT-2 & 15.59 & 13.63 & 16.42 & 4.35 & 5.31 & 2.49 \\
\hline & TT-3 & 12.44 & 10.15 & 11.45 & 2.25 & 4.23 & 3.48 \\
\hline
\end{tabular}

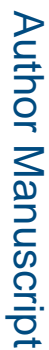

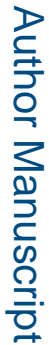




\section{Table 2}

CD4 and CD8 criteria for patients with with diverse, non-MS, chronic neuroinflammatory disease (2 with myasthenia gravis, 2 with Devic's disease and 1 with neurosarcoidosis).

\begin{tabular}{|l|l|l|l|}
\hline Patient\# & CD4/CD45RO+<65\% & CD8/CD28(-)<25\% & Combined Criteria \\
\hline 1 & $\sqrt{ }$ & $\sqrt{ }$ & $\sqrt{ }$ \\
\hline 2 & $\sqrt{ }$ & - & $\sqrt{ }$ \\
\hline 3 & - & $\sqrt{ }$ & $\sqrt{ }$ \\
\hline 4 & $\sqrt{ }$ & $\sqrt{ }$ & $\sqrt{ }$ \\
\hline 5 & - & $\sqrt{ }$ & $\sqrt{ }$ \\
\hline
\end{tabular}

